\title{
Nuevas tecnologías para el desarrollo de la industria turística en Guanajuato, México
}

\author{
Mónica Isabel Mejía Rocha \\ Universidad de Guanajuato (México) \\ monica_mr47@hotmail.com
}

Recibido: 02-07-2015

Aceptado: 12-07-2015

Keywords: Hotels; restaurants; new technologies; marketing; products; services; development.

\section{ABSTRACT}

News technologies for the development of the tourism industry in Guanajuato, México. This exploratory work exposes an assessment of use the technologies of information and communication (TIC's) in 175 tourism businesses in the city of Guanajuato. Among the main results, it was found that the majority of companies including at least one this technology for development of their daily activities. Among the most recurrent technologies are: Data processors, terminals for debit o credit card, websites, social networks and seekers. In this study it can be concluded that the inclusion of new technologies in the tourism industry area invariably associated with its development of tourism in a given destination.
Palabras clave: Hoteles; restaurantes; nuevas tecnologías; comercialización; productos; servicios; desarrollo.

\section{RESUMEN}

El presente trabajo, trabajo de tipo exploratorio, expone un diagnóstico sobre la utilización de las tecnologías de información y comunicación (TIC'S) en 175 empresas turísticas de la ciudad de Guanajuato. Dentro de los principales resultados se pudo encontrar que la gran mayoria de las empresas incluye al menos una TIC para el desarrollo de sus actividades diarias. Dentro de las tareas más recurrentes en las cuales se encuentran dichas tecnologias son: comercialización, administración y servicio al cliente. Las TIC's con mayor recurrencia en la muestra fueron: Procesadores de datos, terminales punto de venta, páginas web, redes sociales y globalizadores. De este trabajo se puede concluir que la inclusión de nuevas tecnologias en la industria del turismo se asociará de manera invariable con el desarrollo del turismo en un destino dado.

\section{INTRODUCCIÓN}

Las tecnologias de Información y Comunicación (TIC's) pueden incidir favorablemente en la evolución de las organizaciones, la esencia de estas radica en favorecer la conectividad que genera el internet, además de promover la construcción y transferencia de información y conocimiento (Dewett y Jones, 2001) entre los clientes internos o externos que las utilicen.

La velocidad con la que el comercio electrónico se relaciona con la sensibilización, adecuación y utilización de las tecnologías de comunicación e información del interesado en vender más, en donde se da además la comodidad de vender desde su lugar de origen sin tener que tocar puerta a puerta (Domínguez, Richard y Castro, 2006). Al hablar de 
marketing virtual, se considerara al menos: páginas web, comerciales por internet, blogs, redes sociales, buscadores entre otros.

El desarrollo de la actividad turística en el estado de Guanajuato se impulsa cada día más, de manera que en el año 2014, se registró un derrama económica de 72, 030 millones de pesos, con 22.2 millones de visitantes, de los cuales, 1 millón 118 mil visitantes fueron internacionales, observándose también, un incremento en la ocupación hotelera del $45.80 \%$ en el mes de abril al $51.60 \%$ al mes de noviembre del mismo año, así lo afirma la Secretaria de Turismo del estado de Guanajuato (SECTUR).

La ciudad de Guanajuato, donde se realizó el estudio, fue en el año de 1985 declarada por la UNESCO como Ciudad Patrimonio de la Humanidad. En el mes de julio del año pasado, registro una llegada de turistas superior a los 80 mil turistas, con un porcentaje de ocupación del $52 \%$ reflejando un incremento del $11 \%$ en relación al año inmediato anterior, en ese mismo mes. En el periodo vacacional de Semana Santa (2015), se enlisto dentro de las seis primero destinos coloniales visitados en el país México.

Según el más reciente (Septiembre, 2015) Inventario Turístico de Establecimientos de hospedaje y Alimentación, generado por el Observatorio Turístico de la Secretaria de Turismo del Estado de Guanajuato la ciudad de Guanajuato incluye en su oferta de hospedaje para el turista 133 establecimientos, cifra que lo coloca en el primer lugar en relación con el resto de las ciudades del Estado. En cuanto a establecimiento de alimentos y bebidas, la misma fuente, asegura que en el estado de Guanajuato existen registrados 821 establecimiento y en la ciudad de Guanajuato 93, colocándose en el lugar número tres en relación a los demás municipios, mostrando ventaja sobre este, la ciudad de León con 128 unidades económicas y la ciudad de Irapuato en segundo lugar con 95 restaurantes (Tabla $1,1)$.

Tabla 1.1. Industria Turística en la ciudad de Guanajuato, en relación a otros municipios del Estado

\begin{tabular}{|c|l|c|l|c|}
\hline Lugar & Municipio & $\begin{array}{c}\text { Número de } \\
\text { establecimientos } \\
\text { de Hospedaje } \\
\text { (Hoteles) }\end{array}$ & Municipio & $\begin{array}{c}\text { Numero de } \\
\text { establecimiento } \\
\text { de Alimentos y } \\
\text { Bebidas } \\
\text { (Restaurantes) }\end{array}$ \\
\hline 1 & Guanajuato & 133 & León & 128 \\
\hline 2 & León & 130 & Irapuato & 95 \\
\hline 3 & $\begin{array}{l}\text { San Miguel de } \\
\text { Allende }\end{array}$ & 115 & Guanajuato & 93 \\
\hline 4 & Irapuato & 34 & Salamanca & 61 \\
\hline 5 & Silao & 30 & San Miguel de Allende & 40 \\
\hline 6 & Celaya & 28 & Acámbaro & 35 \\
\hline 7 & $\begin{array}{l}\text { Dolores Hidalgo } \\
\text { CIN }\end{array}$ & 18 & $\begin{array}{l}\text { Dolores } \\
\text { Guanajuato }\end{array}$ \\
\hline 8 & Salamanca & 17 & Celaya & 32 \\
\hline 9 & Jerécuaro & 7 & Silao & 31 \\
\hline 10 & Jaral & 6 & $\begin{array}{l}\text { San Francisco del } \\
\text { Rincón }\end{array}$ \\
\hline
\end{tabular}

Fuente: Elaboración propia a partir OTEG.

La tabla anterior permite identificar la capacidad de representación que presenta la ciudad de Guanajuato en materia de industria turística en establecimientos de hospedaje (hoteles) y alimentación (restaurantes), esto a fin de mostrar la importancia del objeto de estudio para este trabajo. El presente trabajo muestra describe la inclusión de las Tecnologías de Información y Comunicación en las organizaciones de la industria turística de la ciudad de Guanajuato para su desarrollo. 


\subsection{Tecnologias de Información y Comunicación}

Las Tecnologías de Información y Comunicación (TIC's) propulsan la información en los tiempos actuales mediante el avance de las plataformas digitales y redes de comunicación, suprimiendo cada vez más las barreras que inhiben la transferencia de la misma. En la década de los setentas del siglo pasado, las TIC's revolucionaron al mundo e invariablemente al gerencial provocando su interés, reconociéndolas como elementos estratégicos para la organización, en el año de 1992, Drucker aseguro que se originaba una nueva oleada, en donde las TIC's se posicionarian favorablemente en el contexto mundial.

Las TIC's son consideradas como elementos de soporte importante para las organizaciones actuales, pero para que sean consideradas como tal, deben de identificarse las que son necesarias para cada entidad dependiendo de sus características y necesidades y que su implementación sea de manera mesurada (Nava, 2011). Estas herramientas juegan un papel muy importante en el quehacer cotidiano, puesto que ofrecen diversos servicios como: comercio electrónico, banca online, acceso a contenidos informativos y de ocio, así como también el acceso a la administración pública y a la educación. Esto permite la generación de nuevas modalidades de comunicación, interacción y socialización de la información, eliminando así las barreras de espacio temporales.

\subsection{El comercio electrónico y turismo}

Las sociedades actuales se desenvuelven en contextos donde el crecimiento de la producción, la movilidad de las personas, la reserva y pago de servicios utilizan cada vez más de las tecnologías de información y comunicación. La informática y las comunicaciones facilitan el estado de libertad para la circulación del capital (Molina, 2007).

La mercadotecnia presenta una asociación directa con la imagen de la empresa, razón por la cual, la implicación de las TIC's en esta función organizativa suele ser sustancial (Álvarez, 1998; Flavián y Guerra, 2004; Torres-Fuchslocher y Fuente-Mella, 2011;), dando origen al surgimiento de conceptos tales como: e-bussines, e-comerce, $e$ marketing, por mencionar sólo algunos.

La informática se ha posicionado cada vez más entre las empresas turísticas como una herramienta poderosa de comunicación para sus clientes (Luque y Castañeda, 2007) y que permite favorecer su potencial competitivo, de igual manera el desarrollo del turismo como tal (Przybylski, 1995). Dentro de las ventajas que la industria turística en su proceso de mercadotecnia puede presentar al integrar en el mismo la tecnologías de información y comunicación serian al menos: accesibilidad para los turistas, comodidad de negociación y reservación de espacios y fechas, rapidez de organización de viaje, innovación en el viaje, flexibilidad de adecuaciones de viaje antes de su llegada al destino, reducción en el costo de sus operación de planificación de viaje al no recurrir de agentes o intermediarios, entre otros (Hijazi, 2002 y Rivero, 2006).

El internet fue considerado en un principio como la plataforma ideal para presentar y promocionar productos y servicios en el ámbito turístico (López, 2007). Posteriormente, los sitios electrónicos, permiten no solo hacer compras, sino que además estos espacios se muestran más interactivos, atractivos para el cliente (Polo, 2009), aun a pesar de la inseguridad representada también para el consumidor de servicios turísticos ante este tipo de transacciones comerciales. Herramientas como el $e$ - marketing directo, como correo electrónico pueden representar seguridad para los consumidores.

Las condiciones de los mercados turísticos se han transformado con la implementación y desarrollo de las tecnologías de información y comunicación, previendo beneficios tales como el valor añadido al producto o servicio que estas ofrecen (Ruiz y 
Moliner, 2009). En el contexto turístico, el entorno digital favorece la comunicación directa entre el turista y el destino que pretende visitar, otorgándole al primero de estos, la posibilidad de preconocer y seleccionar no solo un destino, sino además parte de los servicios o productos que este consumirá durante su estancia, si así lo desea (Vela, 2012), así mismo, el prestador de servicios turísticos han dejado de depender casi en su totalidad de intermediarios o mayoristas, cediendo sus espacios y disponibilidad al cliente de manera directa a través de las TIC's (Martínez, 2014).

Los buscadores turísticos, sitios Web que generalmente atienden a clientes y que le muestran ofertas posibles sobre sus requerimientos particulares. El comercio electrónico, permite, quien asî lo requiera, conocer el grado de satisfacción o insatisfacción de los usuarios pasados del servicio o producto que el turista potencial pretende visitar, acción que puede contribuir en su poder de decisión.

Un informe emitido por iPerceptions demostró que el 27\% de visitantes de un destino identifican a este desde los buscadores electrónicos; además, el estudio permitió conocer que una vez que el futuro turista se encuentra en estos buscadores sus filtros comienzan a partir de identificar los mejores precios (20\%); este mismo estudio, afirmó que de los turistas de un lugar, el 64\% suele compartir en redes sociales sus experiencias en el destino visitado, que de estos, el 94\% comparte sus experiencias malas y el $70 \%$ casi nunca habla de las experiencias positivas.

Dentro de los buscadores en la web que ofertan servicios de hospedaje o alimentación en México se puede mencionar: Booking.com, Tripadvisor.com, Zona Turística, Hoteles.com, Mi nube; Destina, Rastreador de hoteles.com, Atrapalo.com, entre otros.

\section{MÉTODOS, MATERIALES Y RESULTADOS}

Este trabajo se realizó en tres etapas, la primera en identificar la importancia de la industria hotelera y restaurantera para el desarrollo del turismo en la entidad, lo anterior haciendo un análisis de lo registrado en el organismo oficial que regula la actividad turística en el estado de Guanajuato, la Secretaria de Turismo. Los resultados permitieron determinar la muestra quedando integrada por 226 establecimientos (Tabla 3.1).

Tabla 3.1.Conformación de la muestra

\begin{tabular}{|c|c|c|c|}
\hline $\begin{array}{c}\text { Tipo de } \\
\text { establecimiento }\end{array}$ & $\begin{array}{c}\text { Población según } \\
\text { Inventario } \\
\text { Turistico } \\
\text { SECTUR, 2014 }\end{array}$ & $\begin{array}{c}\text { Grado de } \\
\text { confiabilidad y } \\
\text { error }\end{array}$ & $\begin{array}{c}\text { Total de } \\
\text { muestra }\end{array}$ \\
\hline Hospedaje & 133 & $\begin{array}{c}95 \% \\
\text { Confiabilidad } \\
5 \% \text { Error }\end{array}$ & 99 \\
\cline { 1 - 1 } & 93 & & 76 \\
\hline Restaurantes & & & 175 \\
\hline
\end{tabular}

Fuente: Elaboración propia

Posteriormente se aplicó un cuestionario a los representantes de establecimientos requeridos según la muestra estimada para conocer acerca de la utilización de la TIC's en sus establecimientos; posteriormente se analizó si es que existían o no páginas web de dichos establecimientos, así como la información de estos encontrada en los buscadores más recurrentes para la distribución de productos y servicios del turismo. Los datos encontrados fueron analizados desde la estadística descriptiva, para finalizar con la elaboración de conclusiones e integración del presente trabajo.

Como resultado del cuestionario aplicado a representantes de los establecimientos de hospedaje y alimentación, se pudo conocer que al interior de estas organizaciones, la mayoria de ellas utiliza al menos una tecnología de información y comunicación para el 
desarrollo de sus actividades de administración, actualización y/o comercialización (Tabla 3.2).

Tabla 3.2. Resultados en la organización sobre el uso de las TIC's para su operación.

\begin{tabular}{|c|c|c|c|}
\hline & Pregunta & Hoteles & Restaurantes \\
\hline 1.- & $\begin{array}{l}\text { ¿Se promueve la utilización de } \\
\text { las TIC`s para el desempeño de } \\
\text { las funciones en la } \\
\text { organización? }\end{array}$ & $\begin{array}{l}\text { Siempre }(65 \%) \\
\text { Casi siempre }(28 \%) \\
\text { A veces }(5 \%) \\
\text { Casi Nunca }(2 \%)) \\
\text { Nunca }(0 \%)\end{array}$ & $\begin{array}{l}\text { Siempre }(35 \%) \\
\text { Casi Siempre }(28 \%) \\
\text { A veces }(26 \%) \\
\text { Casi Nunca }(8 \%) \\
\text { Nunca }(3 \%)\end{array}$ \\
\hline $2 .-$ & $\begin{array}{l}\text { ¿Qué funciones de la } \\
\text { organización son apoyadas por } \\
\text { las TIC's? } \\
\text { Administración, } \\
\text { Comercialización, Facturación, } \\
\text { IMSS }{ }^{1} \text {. }\end{array}$ & $\begin{array}{l}\text { Todas }(31 \%) \\
\mathrm{Al} \text { menos } 2 \text { de estas } \\
(63 \%) \\
\text { Una de estas }(6 \%) \\
\text { Ninguna de estas }(0 \%)\end{array}$ & $\begin{array}{l}\text { Todas }(15 \%) \\
\text { Al menos } 2 \text { de estas } \\
(76 \%) \\
\text { Una de estas }(6 \%) \\
\text { Ninguna de estas }(3 \%)\end{array}$ \\
\hline 3.- & ¿Qué tipo de TIC's se utilizan? & $\begin{array}{l}\text { Procesadores de textos } \\
(100 \%) \\
\text { Terminales punto de } \\
\text { venta }(100 \%) \\
\text { Página Web }(66 \%) \\
\text { Software de facturación } \\
(80 \%) \\
\text { Software para IMSS } \\
(65 \%) \\
\text { Redes Sociales para la } \\
\text { comercialización }(78 \%)\end{array}$ & $\begin{array}{l}\text { Procesadores de textos } \\
(85 \%) \\
\text { Terminales punto de } \\
\text { venta }(78 \%) \\
\text { Página Web }(42 \%) \\
\text { Software de facturación } \\
(76 \%) \\
\text { Software para IMSS } \\
(38 \%) \\
\text { Redes Sociales para la } \\
\text { comercialización }(36 \%)\end{array}$ \\
\hline 4.- & \begin{tabular}{lcr} 
¿De qué & manera & la \\
organización & \multicolumn{2}{c}{ obtiene } \\
información & para & su \\
actualización & constante? &
\end{tabular} & $\begin{array}{l}\text { Internet }(82 \%) \\
\text { Capacitación Interna } \\
(76 \%) \\
\text { Fuentes Oficiales }(68 \%) \\
\text { Otros Medios }(12 \%) \\
\end{array}$ & $\begin{array}{l}\begin{array}{l}\text { Internet }(73 \%) \\
\text { Capacitación Interna } \\
(70 \%)\end{array} \\
\text { Fuentes Oficiales }(36 \%) \\
\text { Otros Medios (14\%) } \\
\end{array}$ \\
\hline 5.- & $\begin{array}{l}\text { ¿El establecimiento cuenta con } \\
\text { algún sistema de Intranet, para } \\
\text { la comunicación entre } \\
\text { colaboradores? }\end{array}$ & $\begin{array}{l}\mathrm{Si}(35 \%) \\
\text { No }(65 \%)\end{array}$ & $\begin{array}{l}\text { Si }(12 \%) \\
\text { No }(88 \%)\end{array}$ \\
\hline 6.- & $\begin{array}{l}\text { ¿Los reportes generados en la } \\
\text { organización son realizados con } \\
\text { el apoyo de alguna TIC? }\end{array}$ & $\begin{array}{l}\mathrm{Si}(93 \%) \\
\text { No }(7 \%)\end{array}$ & $\begin{array}{l}\text { Si }(67 \%) \\
\text { No }(33 \%)\end{array}$ \\
\hline 7.- & $\begin{array}{l}\text { ¿Cómo se resguardan dichos } \\
\text { reportes? }\end{array}$ & $\begin{array}{l}\text { Archivos Digitales }(93 \%) \\
\text { Plataformas }(15 \%) \\
\text { En texto }(88 \%)\end{array}$ & $\begin{array}{l}\text { Archivos Digitales } \\
(56 \%) \\
\text { Plataformas }(2 \%) \\
\text { En texto }(94 \%) \\
\end{array}$ \\
\hline 8.- & $\begin{array}{l}\text { ¿'Se le proporciona al personal } \\
\text { actualización sobre las } \\
\text { tecnologias de información y } \\
\text { comunicación? }\end{array}$ & $\begin{array}{l}\text { Siempre }(55 \%) \\
\text { Casi Siempre }(22 \%) \\
\text { A veces }(11 \%) \\
\text { Casi Nunca }(8 \%) \\
\text { Nunca }(3 \%)\end{array}$ & $\begin{array}{l}\text { Siempre }(12 \%) \\
\text { Casi Siempre }(34 \%) \\
\text { A veces }(44 \%) \\
\text { Casi Nunca }(6 \%) \\
\text { Nunca }(4 \%)\end{array}$ \\
\hline 9.- & $\begin{array}{l}\text { ¿Qué porcentaje de la plantilla } \\
\text { de personal utiliza para sus } \\
\text { labores al menos alguna TIC? }\end{array}$ & $\begin{array}{l}100 \%(58 \%) \\
75 \%(33 \%) \\
50 \%(14 \%) \\
25 \%(5 \%)\end{array}$ & $\begin{array}{l}100 \%(5 \%) \\
75 \%(13 \%) \\
50 \%(15 \%) \\
25 \%(19 \%)\end{array}$ \\
\hline
\end{tabular}

\footnotetext{
${ }^{1}$ Instituto Mexicano del Seguro Social. Institución Mexicana que presta seguridad social a los trabajadores.
} 


\begin{tabular}{|c|c|c|c|}
\hline & & Menos del 25\% (6\%) & Menos del 25\% (48\%) \\
\hline 10.- & $\begin{array}{l}\text { ¿Considera que las TIC's son } \\
\text { importante para el desarrollo } \\
\text { del turismo? }\end{array}$ & $\begin{array}{l}\text { Totalmente de acuerdo } \\
(62 \%) \\
\text { De acuerdo (29\%) } \\
\mathrm{Ni} \mathrm{en} \mathrm{acuerdo} \mathrm{ni} \mathrm{en} \\
\text { desacuerdo }(5 \%) \\
\text { En desacuerdo }(2 \%) \\
\begin{array}{l}\text { Totalmente } \\
\text { desacuerdo (2\%) }\end{array} \\
\end{array}$ & $\begin{array}{l}\text { Totalmente de acuerdo } \\
(22 \%) \\
\text { De acuerdo }(24 \%) \\
\mathrm{Ni} \text { en acuerdo ni en } \\
\text { desacuerdo }(25 \%) \\
\text { En desacuerdo }(19 \%) \\
\text { Totalmente en } \\
\text { desacuerdo }(10 \%)\end{array}$ \\
\hline
\end{tabular}

Fuente: Elaboración propia.

En la tabla anterior se puede observar que dentro de la industria turística, los establecimientos de hospedaje muestran mayor predisposición y apertura a las TIC's para su uso en la operación de su empresa, mientras que los establecimientos de preparación y distribución de alimentos no consideran el mismo grado de importancia a dichas tecnologías para el desarrollo de su negocio. Es importante considerar como existen diferencias marcadas en cuanto a la actualización que la empresa proporciona al personal en TIC's hacia los colaboradores entre los hoteles y restaurantes, así mismo la importancia que estos dos tipos de establecimientos dan a estas herramientas para el desarrollo del turismo, pues desde la parte de los restaurantes se afirma que el servicio y el sazón de los alimentos son elementos esenciales para su permanencia en el mercado y contribuir con esto al desarrollo del turismo, mientras que en la hotelería son de gran utilidad para los procesos de comercialización. Lo anterior confirmando de alguna manera lo dicho por Luque y Castañeda en el 2007, y mencionado anteriormente en este documento, acerca de que las Tic's son vistas cada vez más por las empresas turísticas como herramientas importantes para su operación.

Posteriormente se realizó una revisión de las páginas web de los establecimientos que mencionaron contar con estas, donde se encontró que el $65 \%$ de estas páginas permite la realización de reservaciones de manera activa, es decir el usuario puede obtener al momento de la operación una confirmación del servicio, mientras que el resto o bien no se puede realizar reservación o bien solo se envian datos para una futura respuesta; el $75 \%$ de los establecimientos ofrece información sobre políticas de cancelación, en caso de establecimientos de hospedaje.

El promedio de imágenes mostradas en las páginas de estos establecimientos varía de 0 a 10 imágenes (35\%), de 21 a 42 imágenes (42\%), 41 a 60 imágenes mostradas $(11 \%)$ y más de 60 imágenes del establecimiento el (12\%). Generalmente las imágenes de estos sitios son imágenes oficiales generadas por el mismo establecimiento.

Los restaurantes que tienen página (55\%), suelen ofrecer imágenes no solo de sus instalaciones sino también de sus menús o algunos de los platillos que los integran. Solo el $35 \%$ de estos sitios permiten la realización de reservaciones y el $80 \%$ muestra un mapa de acceso a su establecimiento.

Dentro de las redes sociales más comentadas por estas empresas en sus páginas web son: Facebook (47\%), Twitter (23\%), Pinterest (11\%) e Instagram (8\%), lo anterior permite afirmar que las redes sociales forman también parte de los procesos de comercialización de este tipo de empresas. Posteriormente se realizó una revisión sobre algunos de los buscadores más mencionados por los mismos empresarios a fin de identificar la manera en las que sus productos y servicios son comercializados en estos espacios.

Cuando se revisó el portal de Tripadvisor, se pudo conocer que cuenta en su listado con 209 opciones de hospedaje, cantidad superior de los establecimientos registrados en el documento oficial de SECTUR, para el visitante en la ciudad, distinguiendo entre cinco categorias de este tipo de establecimientos. El sitio registra 6301 opiniones de los viajeros que habían ya utilizado el servicio. El promedio de imágenes fotográficas como medio publicitario de este tipo de establecimientos es variado, pues algunos establecimientos cuentan con 4 imágenes mientras otros hasta con 354, estas imágenes incluyen no solo las 
registradas por los prestadores de servicios, sino también por las subidas a la plataforma por clientes que acudieron al lugar, una forma más de referencias el lugar. Este portal electrónico además de los comentarios de los clientes, muestra las calificaciones de los establecimientos, considerando en dicha evaluación, su ubicación, calidad del descanso, habitación, servicio, calidad, precio.

Este mismo portal, muestra a los interesados, 163 opciones de establecimiento de preparación y distribución de alimentos, cifra que muestra una diferencia significativa del número de establecimientos registrados en el Inventario Turístico de SECTUR, 2015.

Expedia, otro buscador analizado, suele resaltar dentro de sus filtros de búsqueda las opciones por "Mejor precio garantizado" y "Sin cargos por cancelación". Este buscador toma referencia de los comentarios de los clientes realizados a través de Tripadvisor. En sus elementos de filtros, para clasificar los 47 establecimiento de hospedaje que tiene registrados, considera "Cancelación gratuita", Tiempo de última reservación realizada por otro usuario en horas", "Porcentaje de descuento por compra en línea", que suelen ser de entre el $10 \%$ y hasta el $45 \%$ en algunos de los casos; así como la opción de "Reserve ahora y pague después", opción que en muchas de las veces es preferida por los consumidores electrónicos, esto por la inseguridad que puede representar dicha transacción.

El buscador Trivago incluye en su listado de ofertas de hospedaje 136 hoteles, tres más de los registrados en el Inventario Turístico, los cuales filtra por número de estrellas que categorizan un hotel, precio que va desde los 472 y los 6103 pesos mexicanos por habitación por noche; servicios de internet, desayuno incluido, spa y alberca; además hace comparación de sus tarifas ofertadas según los requerimientos del cliente con otros buscadores tales como Expedia, Amona, Hoteles.com, Booking.com, Despegar.com y Verena.com, lo anterior a fin de mostrar su competencia en el mercado en razón de tarifas ofertadas al cliente por un mismo servicio ante otros competidores. Las opiniones registradas de los clientes son altas, en comparación a otros buscadores, pues estas van desde 48 comentarios como mínimo y 1197 como máximo.

El buscador Despegar enlista sólo 41 hoteles en la ciudad, su punto diferenciador radica en mucho en su forma de pago de las estancias a los clientes, ofreciendo como opciones para el cliente "Pagar al llegar al hotel su reservación", "18 meses sin intereses" y "Cancelación gratis", lo anterior contribuye y se adecua a la inseguridad, que puede representar este tipo de compra - venta para el usuario o consumidor.

En el buscador Booking.com, 66 establecimientos de hospedaje son los que oferta, localizados estos en el municipio de Guanajuato, y cuyas tarifas promedio son de 1084.53 pesos mexicanos por habitación por noches, para hoteles de 3 estrellas; 1537.05 pesos mexicanos para hoteles de cuatro estrellas, mientras que para los hoteles de cinco estrellas la tarifa promedio por habitación por noche que oferta este buscador es de 1982.50 pesos mexicanos.

En Zona Turística, otro buscador más, se enlistan 95 hoteles y el objetivo principal de este buscador considere en filtrar dichos establecimientos por precio, categoría y servicios que ofrecen, además de exponer las características principales de cada uno de los establecimientos enlistados en su portal.

Siguiendo con el análisis, se encontró que en el buscador Price Travel, se encontraron solo 22 hoteles registrados de los cuales se filtran por tipo de interés del viajero para hacer las recomendaciones, siendo estas opciones: de negocios, ofertando 10 opciones; de familia, 2 opciones; y de romance 1 opción.

Para finalizar se analizó el buscador Verene.com, en el cual se encontraron enlistados 70 hoteles de 1 a 4 estrellas y que dentro de sus elementos estratégicos, ofrece ofertas especiales, "Cancelación gratis", "Pague ahora o en el hotel al llegar".

\section{CONCLUSIONES}


Al hablar de e-marketing en la industria turística resulta ineludible el considerar los buscadores electrónicos de ofertas de hospedaje que permiten al viajero, no solo conocer las mejores opciones en precio, características de los establecimientos y servicios, además de conocer lo que otras personas, usuarios anteriores del servicio, expresan acerca de su experiencia en el lugar, elementos que impactaran definitivamente en la decisión del consumidor turistico.

Los comentarios expresados por los clientes de estos servicios pueden no solo servir a los futuros clientes, también es una información que bien utilizada puede servir a los prestadores de servicios turísticos no solo para medirse y evaluarse desde la opinión del cliente, promoviendo la mejora continua, sino además, conocer de qué manera la competencia se posiciona o no en el mercado que le representa significancia. Esto afirma lo dicho por Font y Andreu (2000), respecto a que la comunicación del turismo va más allá de la publicidad directa y estructurada que pretende emitir el empresario, pues en los tiempos actuales las comunicaciones de los usuarios son buscadas ya también por los que pretenden hacer uso de esas mismas instalaciones a fin de encontrar referencias que les permitan tomar una decisión.

El e-marketing continua evolucionando y se pude esperar a que lo que hoy funciona, mañana, quizás muy pronto resulte obsoleto o de poca utilización.

\section{BIBLIOGRAFÍA}

Bigne, A., Font, A. y Andreu, S. (2000): Marketing de destinos turísticos: Análisis y estrategias de desarrollo, Madrid, ESIC.

Dewett, J. y Jones, G. (2001). "The role of information technology in the organization: a review, model and assessment”, Journal of Management, 3:313-346.

Domínguez, P., Richter, S. y Castro, R. (2006): "Contraste de la capacidad de respuesta a correos electrónicos entre hoteles independientes de cadena", Universidad de las Américas, 15.

Flavián, C. y Guerra, R. (2004): "Nuevas perspectivas de la estrategia de marketing en un entorno virtual", Revista de Gestión Pública y Privada, 9:103 - 114.

Gómez, A. (2005): "Seguridad Informática: funciones y responsabilidades de los empleados y directivos", Capital Humano, 18:68 - 81.

González, I., Torres, J. y Sifuentes, G. (2012): "Uso e implementación de las tecnologías de información y comunicación en la toma de decisiones en los hoteles de la ciudad de Durango", Revista de la Alta Tecnología y la Sociedad, 1: 1-15.

Hizaji, O. (2002): "E-marketing, una inversión con retorno", Deusto, marketing y ventas, 50:6 -11 .

López, J. (2007): "Evolución de los modelos de negocios en Internet", Economía Industrial, 364: $213-229$.

Luque, T. y Castañeda, J. (2007): "Internet y el valor del negocio". Mediterráneo Económico, 11: $397-415$.

Martínez, M. (2014). "El uso de las TICS (Tecnología de la información y comunicación) se ha proliferado dentro del ámbito del turismo convirtiéndose en una herramienta fundamental $y$ un aliado en internet para llegar a conquistar turistas para los diferentes destinos que se promocionan en la web", Revista Turismo y Tecnología.

Molina, V. (2007): "Ocio y turismo en la era de la Globalización", Marketing Trends Congress.

Polo, D. (2009): "La filosofia 2.0 y la explosión audiovisual en internet. Razón y Palabra, 7: $87-96$.

Przybylski, A. (1995): Marketing de servicios turisticos, Argentina: SURPASS

Ruiz, M. y Moliner, V. (2009) : "El uso de las Tecnologias de Información y Comunicación como elemento diferenciador en Hoteles", Gest. Tur, 7:81 - 90.

SECTUR (2015) : "Inventario Turístico del Estado de Guanajuato ", Observatorio Turístico del Estado de Guanajuato. 
Torres-Fuchslocher, C. y Fuente-Mella, H. (2011). "Determinantes de la Innovación en Empresas de Turismo en Pucón - Chile ", Panorama Socio économico, 42 :24-43.

Vela, J. (2012). "Aproximaciones teóricas y conceptuales para una definición del estado del arte de la comunicación de los destinos turísticos ", Revista Andamios, 20 :211-236.

\section{HOW TO CITE THIS ARTICLE IN BIBLIOGRAPHIE}

Mejía Rocha, M. I. (2015): "Nuevas tecnologias para el desarrollo de la industria turística en Guanajuato, Méxic" Rotur. Revista de Ocio y Turismo, 9: 35-43, ISSN-e: 2695-6357, DOI: https://doi.org/10.17979/rotur.2015.9.1.1338 